\title{
Anti-Müllerian hormone and ovarian aging in mares
}

\author{
Renata C Uliani', Alan J Conley², C Jo Corbin², Aimê M Friso', Luciana F S Maciel1 and Marco A Alvarenga1 \\ 1Department of Animal Reproduction, School of Veterinary Medicine and Animal Science, São Paulo State University (UNESP), Botucatu, São Paulo, Brazil \\ 2Department of Population Health and Reproduction, School of Veterinary Medicine, University of California Davis, Davis, California, USA
}

Correspondence should be addressed to R C Uliani or A J Conley: renata.uliani@gmail.com or ajconley@ucdavis.edu

\begin{abstract}
Anti-Müllerian hormone (AMH) is used as a marker of follicle population numbers and potential fertility in several species including horses but limited data exist across the lifespan. No one has decreased ovarian reserve experimentally to investigate whether a corresponding, quantitative decrease in $\mathrm{AMH}$ results. Concentrations of $\mathrm{AMH}$ across the lifespan were compiled from 1101 equine females sampled from birth to $>33$ years of age. Young and old mares (averaging 6 and 19 years) were hemi-ovariectomized and circulating $\mathrm{AMH}$ was assessed before and daily thereafter for 15 days. The remaining ovary was removed later and blood was drawn again before and after this second surgery for AMH determination. Polynomial regression analysis and analysis of mares grouped by 5 -year intervals of age demonstrated AMH concentrations to be higher in mares aged 5-10 and 10-15 years than 0-5 years of age and lower in mares after 20 years of age. There was high variability in AMH concentrations among neonatal fillies, some of which had concentrations typical of males. Hemi-ovariectomy was followed by a decrease of $\mathrm{AMH}$, almost exactly halving concentrations in intact mares. Concentrations of AMH had returned to intact levels in old mares before complete ovariectomy, as if exhibiting ovarian compensatory hypertrophy, but recovery of $\mathrm{AMH}$ was not evident in young mares. AMH may reflect ovarian senescence in mares after 20 years of age but is too variable to do so in the first two decades of life. The ovarian endocrine response to hemi-ovariectomy in mares appears to change with age.
\end{abstract}

Key Words
- ovary
- aging
- anti-Müllerian hormone
- ovarian reserve
- equine

Journal of Endocrinology (2019) 240, 147-156

\section{Introduction}

Anti-Müllerian hormone (AMH) has attracted considerable interest in female reproduction as an indicator of reproductive aging and fertility, predicting the size of follicle populations in the ovaries of women and other mammals including ruminants (Monniaux et al. 2014, Mossa et al. 2017) and horses (Claes et al. 2015). Our current understanding of female reproductive longevity assumes that the ovaries contain a finite number of oocytes, comprising the pool of primordial and developing follicles (Gougeon 1996, Monget et al. 2012), which is often referred to as 'ovarian reserve'. Ovarian reserve declines with age as follicles are lost (Gosden \& Faddy 1998) and oocyte depletion or senescence with age heralds the loss of fertility (Wallace \& Kelsey 2010). $\mathrm{AMH}$ is secreted by follicles, thereby providing an index of existing follicle numbers. It is positively associated with productive herd life (Jimenez-Krassel et al. 2015) and is a general index of responsiveness to super-ovulation and perhaps fertility in cattle (Ireland et al. 2011). However, because the level of AMH secretion from follicles changes 
with their stage of development (Knight \& Glister 2006, Monniaux et al. 2014, Mossa et al. 2017), $\mathrm{AMH}$ secretion will be influenced by the follicle population distribution (defined by diameter) as well as the existing numbers within each stage. Assessing the degree to which identifiable follicle populations contribute to circulating $\mathrm{AMH}$ is challenging and species are likely to differ in this regard, as they do in other aspects of the regulation of follicular growth (Fortune 1994, Knight \& Glister 2006, Monniaux et al. 2014). Therefore, the degree to which $\mathrm{AMH}$ reflects ovarian reserve and fertility must be defined carefully for each species. Furthermore, while carefully controlled laboratory studies help to establish what can be regarded as normal, these generally utilize very limited numbers of subjects and more extensive, fieldbased work is needed to assess the practically relevant normal limits.

As with ovarian exhaustion in women (van Disseldorp et al. 2008), other primates (Appt et al. 2010) and rodent species (Kevenaar et al. 2006, Yeh et al. 2007), $\mathrm{AMH}$ concentrations were shown to decline with age in mares and to correlate positively with antral follicle count (AFC), especially in aging mares over 19 years of age (Claes et al. 2015). To date however, few studies have evaluated in a quantitative way how accurately experimentally induced changes in ovarian reserve are predicted by $\mathrm{AMH}$, in part because of the difficulty in counting or estimating total follicle population numbers (Hansen \& Soules 2008). Studies in both rodents (Smith et al. 1990) and primates (Appt et al. 2010) have utilized the ovarian toxicant, 4-vinylcyclohexene diepoxide (VCN) to effectively destroy primordial and other pre-antral follicles (Hoyer \& Sipes 1996, Van Kempen et al. 2011) and thereby advance ovarian senescence. Those that have also measured AMH have demonstrated a profound reduction in the days and weeks that follow, significantly correlated with AFC (Sahambi et al. 2008, Appt et al. 2009, Mark-Kappeler et al. 2010). How quantitatively this reflects a decrease in follicle numbers is unknown. Recent observations on the response to immuno-contraception in mares indicated that vaccination against porcine zona pellucida also dramatically decreased AMH concentrations (Joone et al. 2018). However, studies in reproductively seasonal species demonstrate that $\mathrm{AMH}$ is far from a perfect index of fertility and subject to considerable, unexplained individual variability (Roosa et al. 2015). Similar observations of poor correlations between $\mathrm{AMH}$ and the chances of establishing pregnancy have been reported among both fertile women (Streuli et al. 2014) and those seeking fertility services (Casadei et al. 2013).
Assessment of follicle populations along with $\mathrm{AMH}$ concentrations is unusually difficult in mares given their size, shape and organization of the ovary and the follicles within (Walt et al. 1979). AFC can be performed by imaging but only with a resolution limit of $1-2 \mathrm{~mm}$. Unfortunately, the overall size and unusual asymmetry of equine ovaries (Walt et al. 1979) makes an accurate, histological assessment of the small follicle populations (most likely to contribute significantly to AMH secretion) problematic. Consequently, only a single published report has detailed follicle numbers that includes pre- as well as post-antral developmental stages in equine ovaries, noting extreme individual variation in both pony and saddletype mares (Driancourt et al. 1982b) at all stages. AntiMüllerian hormone is thought to be secreted by pre- and early antral follicles (Knight \& Glister 2006, Ball et al. 2008, Monniaux et al. 2014, Mossa et al. 2017), far smaller than the smallest follicles that can be counted by non-invasive techniques. Thus, the positive correlations that have been found between $\mathrm{AMH}$ and $\mathrm{AFC}$ are likely to reflect the close association between peri-antral and antral follicle numbers but, depending on age, perhaps not primordial follicles (Block 1952, Driancourt et al. 1982b). In any case, to the best of our knowledge, the impact of experimental reduction of ovarian reserve on $\mathrm{AMH}$ concentrations has never been investigated in a large animal species or in a truly quantitative way in any species.

The following studies were undertaken with two principal goals. First, to conduct an extensive field study of the variation of AMH concentrations with age among a large population of mares. We sought to test the hypothesis that, despite a continual loss of follicles with age each breeding season in mares, $\mathrm{AMH}$ concentrations do not change predictably until late in their reproductive lives. Second, to validate the measurement of $\mathrm{AMH}$ as quantitatively reflecting ovarian follicular reserve in individual mares, we hypothesized that decreasing total follicle numbers would result in a correlated decrease in AMH. To test this hypothesis, we investigated AMH concentrations in young and old mares subjected to hemi-ovariectomy, as the only practical experimental approach to quantifiably manipulate ovarian reserve (decrease it by half) in this species.

\section{Materials and methods}

All animal procedures in this experiment were approved by São Paulo State University, according with the Brazilian National Committee of Control in Animal Experimentation - CONCEA (CEUA protocol 27/2016). 


\section{Experiment 1: serum concentrations of AMH across the lifespan}

A single blood sample was collected randomly without regard for the stage of the estrous cycle, but within a 2-month period (mid-February to mid-April) in the same breeding season, from a total of 1101, registered, nonpregnant Quarter Horse mares $(n=1058)$ and newborn filly foals $(n=43)$, housed at 23 ranches in Brazil. Mares were in good body condition at the time of sampling. Ages were confirmed by birth registry entries. Ages ranged from birth to $>33$ years of age (Fig. 1). Blood samples were drawn from the jugular vein, centrifuged $(1500 \boldsymbol{g}$ for $10 \mathrm{~min})$ and serum was harvested and stored frozen $\left(-20^{\circ} \mathrm{C}\right)$.

\section{Experiment 2: effects of hemi-ovariectomy on AMH concentrations in young and old mares}

Six younger mares $(6.0 \pm 0.8$ years of age, range 3-8) and six older mares (18.7 \pm 0.5 years of age, range 18-20) underwent unilateral ovariectomy. These were of mixed breed and all in good body condition, with no known history of infertility. All were apparently reproductively sound and cyclic based on a clinical evaluation that included an ultrasound examination of the reproductive tract and ovaries every other day for a complete cycle. Mares received $4 \mathrm{~kg}$ of pelleted horse feed, $6 \mathrm{~kg}$ of tifton hay and mineral salt and water ad libitum for the duration of the treatment protocol and were assigned to the study without regard to stage of the cycle.

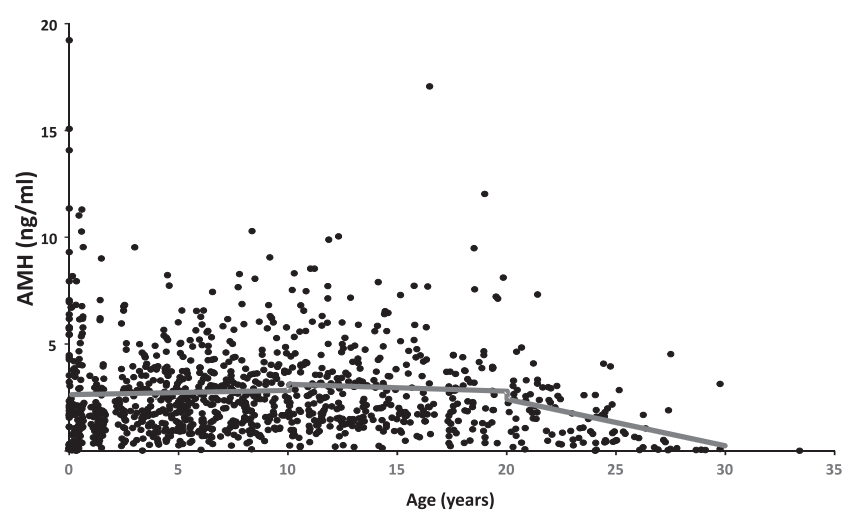

Figure 1

Concentrations of anti-Müllerian hormone $(\mathrm{AMH}, \mathrm{ng} / \mathrm{mL})$ in populations of mares $(N=1101)$ sampled at various ages ranging from birth to $>33$ years of age. Changes in $\mathrm{AMH}$ concentrations with age were analyzed by linear regression analysis performed based on mare ages $(0-10,11-20$ and $>20$ years of age). Linear regression was not significant for ages $0-10$ $(P>0.41)$ or $11-20(P>0.48)$ years of age, but declined significantly with age in mares $>20$ years of age $(P<0.001)$.

C) 2019 Society for Endocrinology Published by Bioscientifica Ltd. Printed in Great Britain
A blood sample was collected before surgery and every day for 15 days following surgery. Serum was harvested after centrifugation $(1500 \boldsymbol{g}$ for $10 \mathrm{~min})$ and stored for analysis $\left(-20^{\circ} \mathrm{C}\right)$. These samples were also included in a recently published, unrelated study evaluating inhibin-A and -B concentrations (Conley et al. 2017). Unilateral ovariectomy was performed standing through a vertical flank incision of approximately $15 \mathrm{~cm}$ in length under sedation (detomidine, $20 \mu \mathrm{g} / \mathrm{kg}$ ) and local anesthesia was induced by lidocaine infiltration. Hemi-ovariectomy was performed at random with respect to cycle stage which was verified by gross examination of ovaries and progesterone concentrations in peripheral blood (Munro \& Stabenfeldt 1984) (data not shown). Based on previous studies in pony mares, follicle distribution is equal between left and right ovaries (Driancourt et al. 1982a). An incision was made over the lumbar fossa and muscle tissues separated bluntly to gain access to the peritoneal cavity. The ovarian pedicle was clamped and ligated with vicryl and the ovary removed. The skin incision was closed with non-absorbable, braided nylon suture (Braunamid, Aesculap, Center Valley, PA, USA). After surgery, mares were treated with flunixin meglumine (Banamine, $1.1 \mathrm{mg} / \mathrm{kg}$ every $12 \mathrm{~h}$ for 3 days), ceftiofur (Excede $6.6 \mathrm{mg} / \mathrm{kg}$, repeated 4 days later) and antitetanus serum. Mares were examined daily and a jugular blood sample was drawn each day for 2 weeks following unilateral ovariectomy. The mares were evaluated weekly thereafter and, once determined to be in anestrus based on ovarian size and the absence of growing follicles, were again submitted to ovariectomy, to remove the remaining ovary using the same procedure. Blood samples were again drawn immediately before and at 15 days after surgery. The mean interval between the first and second surgery was $111 \pm 24$ days.

AFCs were conducted on all 12 mares by transrectal ultrasonography (A5 - Sonoscape, China) before hemiovariectomy. The follicles of both ovaries were classified according to their size and categorized into groups: group 1 , up to $5 \mathrm{~mm}$; group 2, 6-10 $\mathrm{mm}$; group 3, $11-15 \mathrm{~mm}$; group 4, 16-20 mm; group 5, 21-25 $\mathrm{mm}$; group 6, $26-30 \mathrm{~mm}$; group 7, 31-35 mm; group $8,36-40 \mathrm{~mm}$ and group 9, $>40 \mathrm{~mm}$. Ovaries obtained after removal of the remaining ovary were submitted to MRI for AFC (VET-MR Grande - Esaote, Italy), essentially as described (Leonhardt et al. 2014) using 2D imaging. The images were subsequently evaluated and all detectable follicles present in the ovaries were counted using the same size group classification (Supplementary Table 1, see section on supplementary data given at the end of this article). 


\section{Validation of enzyme-linked immunoassay (ELISA) for AMH}

Serum AMH concentrations were determined using commercially available ELISA kits (Equine AMH ELISA, Ansh Labs, Webster, TX, USA) according to the manufacturer's instructions. Serial dilutions of a serum pool were shown to vary in parallel to the standard curve (Supplementary Fig. 1). The intra- and inter-assay coefficients of variation were 3.8 and $9.9 \%$, respectively, and the assay sensitivity was $0.07 \mathrm{ng} / \mathrm{mL}$. Spiked-recovery experiments were also conducted. A purified human (Pepin et al. 2013, Kano et al. 2017) recombinant AMH (rhAMH) was used to estimate the recovery of AMH added to equine serum. This was added to gelding serum at various concentrations extending over the range of the kit calibrators $(0-15.6 \mathrm{ng} / \mathrm{mL})$ and was replicated $(n=8)$ at a concentration representing the average of measured sample concentrations, $\approx 2 \mathrm{ng} / \mathrm{mL}$. Equine serum quenched the optical density generated in the assay by addition of rhAMH at various concentrations (Supplementary Fig. 2). However, the recovery of AMH calculated from regression analysis across the calibrator range was linear $(y=0.52 x$, $R^{2}=0.99$, Supplementary Fig. 3) and just over $51 \%$. The mean and standard error of the replicates of $\approx 2 \mathrm{ng} / \mathrm{mL}$ purified rhAMH in the assay was $0.89 \pm 0.04 \mathrm{ng} / \mathrm{mL}$. Additional spiked-recovery experiments were conducted using fluid from an equine granulosa-theca cell tumor (GCT) as a source of highly concentrated, native equine AMH (Ball et al. 2008). The fluid measured $18.2 \mu \mathrm{g} / \mathrm{mL}$ of AMH when diluted 1:500 in assay buffer. A titration of the fluid was linear in assay buffer $\left(R^{2}=0.98\right)$ and in equine serum $\left(R^{2}=0.99\right)$. Recovery experiments were conducted by adding $1 \mu \mathrm{L}$ of GCT fluid to $500 \mu \mathrm{L}$ of serum from eight different mares. The average recovery was $88 \pm 6 \%(n=8)$, but included a recovery from one serum sample that was $54 \%$. If this single point was omitted, the recovery was $93 \pm 4 \%$ (range $80-106 \%, n=7$ ). In addition, a subset of samples $(n=43)$ were re-assayed after a freeze-thaw cycle. The concentrations determined in each of these assays were highly correlated $\left(y=1.06 x+0.17, R^{2}=0.99\right.$; Supplementary Fig. 4).

\section{Statistical analysis}

The distribution of AMH concentrations for mares in Experiment 1 was examined for normality using a Shapiro-Wilk test and subjected to linear regression analysis by time for ages $0-10,10-20$ and $>20$ years of age. Data were not normally distributed, nor were they normalized by $\log$ transformation and so were also analyzed by non-parametric methods after categorization into age intervals of 5 years and presented as traditional box plots of medians, ranges and 50\% CIs. Differences in $\mathrm{AMH}$ concentrations among each age range were evaluated using the Kruskal-Wallis test. For Experiment 2, day-by-day changes in AMH after hemi-ovariectomy were analyzed using the GLM procedure (SAS Statistical Software, SAS Institute Inc.) for repeated measures over time with age as a main effect. Differences among means for AMH concentration at sampling before hemiovariectomy (pre-hemi), 15 days after hemi-ovariectomy (post-hemi), before (pre-OVX) and after removal of the remaining ovary (post-OVX) were analyzed using a mixed effect analysis of variance ML linear regression (StataCorp, College Station TX) with age and time as categorical main effects. The potential age *time interaction was examined using a global Wald Test after normality was confirmed using a Shapiro-Wilk test. Comparisons among means were made after applying a Bonferroni adjustment. Means \pm standard errors of the means were graphed.

\section{Results}

Experiment 1: Serum AMH concentrations varied with age but with considerable variation at each age. For instance, concentrations among fillies on the day of birth ranged from $0.26 \mathrm{ng} / \mathrm{mL}$ to $15.47 \mathrm{ng} / \mathrm{mL}$. Overall, linear regression indicated that there was no evidence of declining AMH concentrations until after 20 years of age among these mares (Fig. 1). There was no significant effect of time in mares aged $0-10$ years $(P>0.41)$ or $10-20$ years $(P>0.48)$ but a significant decline with time in mares 20 years of age and older $(P<0.001)$ by linear regression analysis. After grouping mares by 5 -year intervals, AMH concentrations were significantly higher in mares aged 5-10 and 10-15 years of age than those $<5$ years of age and were significantly lower in mares $>20$ years of age $(P<0.05 ;$ Fig. 2$)$. Age groups had the following median concentrations of AMH: $0-5$ years, $1.8 \mathrm{ng} / \mathrm{mL} ; 5-10$ years, $2.4 \mathrm{ng} / \mathrm{mL} ; 10-15$ years, $2.5 \mathrm{ng} / \mathrm{mL} ; 15-20$ years, $2.2 \mathrm{ng} / \mathrm{mL}$; $20-25$ years, $1.8 \mathrm{ng} / \mathrm{mL} ;>25$ years, $0.3 \mathrm{ng} / \mathrm{mL}$.

Experiment 2: Young and old mares had similar AMH concentrations before hemi-ovariectomy $(1.03 \pm 0.08$ and $0.96 \pm 0.18 \mathrm{ng} / \mathrm{mL}, P>0.1)$. Concentrations of $\mathrm{AMH}$ decreased progressively reaching a nadir about a week after surgery in both young and old mares (Fig. 3). Combining the data from the young and old mares, $\mathrm{AMH}$ concentrations decreased by a little more than half from 


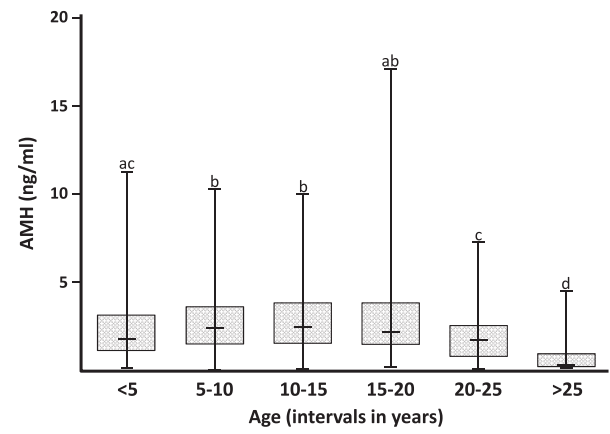

Figure 2

Non-parametric analysis of concentrations of anti-Müllerian hormone $(\mathrm{AMH}, \mathrm{ng} / \mathrm{mL})$ in populations of mares, grouped by 5 -year age ranges $(N=1058 ;<5$ years, $n=399 ; 5-10$ years, $n=272 ; 10-15$ years, $n=193$; $15-20$ years, $n=110 ; 20-25$ years, $n=64 ;>25$ years, $n=20$ ). Data from day-old fillies $(n=43)$ were omitted from this analysis. Shown are the median concentrations, ranges and $50 \%$ confidence intervals. AMH concentrations in intervals marked by different superscript differ, $P<0.05$.

$1.00 \pm 0.01 \mathrm{ng} / \mathrm{mL}$ before surgery to $0.46 \pm 0.01 \mathrm{ng} / \mathrm{mL}$ 15 days after surgery $(P<0.001)$. The elimination halflife was estimated based on samples taken from days $0-5$ over which time concentrations of AMH declined with a half-life of 3.7 days. Seven mares were in the luteal phase (progesterone $>1 \mathrm{ng} / \mathrm{mL}$ ) when hemi-ovariectomy was performed. Based on the subsequent, rapid disappearance of progesterone, the ovary removed contained the corpus luteum (CL) in two of those mares, neither of which re-ovulated in the 15 days monitored after surgery. Of the five other mares, luteolysis occurred 14, 13, 11 and 11 days after surgery and one did not experience luteolysis during the monitoring period. Thus, none of the seven mares with CL at the time of surgery ovulated in the 15 days monitored after surgery. Six mares did not have functional CL when hemi-ovariectomy was performed. One ovulated

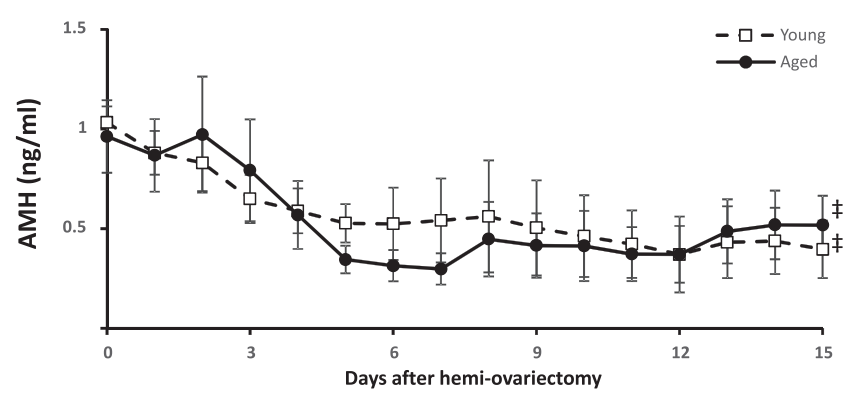

Figure 3

Concentrations of anti-Müllerian hormone $(\mathrm{AMH}, \mathrm{ng} / \mathrm{mL})$ in young ( $6.0 \pm 0.8$ years, dashed line, $n=6)$ and old mares $(18.7 \pm 0.5$, solid line, $n=6$ ) in jugular blood drawn before (day 0 ) and daily after hemiovariectomy. Concentrations of AMH decreased significantly from day 0 (pre-hemi-ovariectomy) to day $15\left({ }^{\ddagger} P<0.001\right)$ after surgery, but there was no main effect of age or age * time interaction, and there was no difference in $\mathrm{AMH}$ between young and old mares on day $0(P>0.5)$.

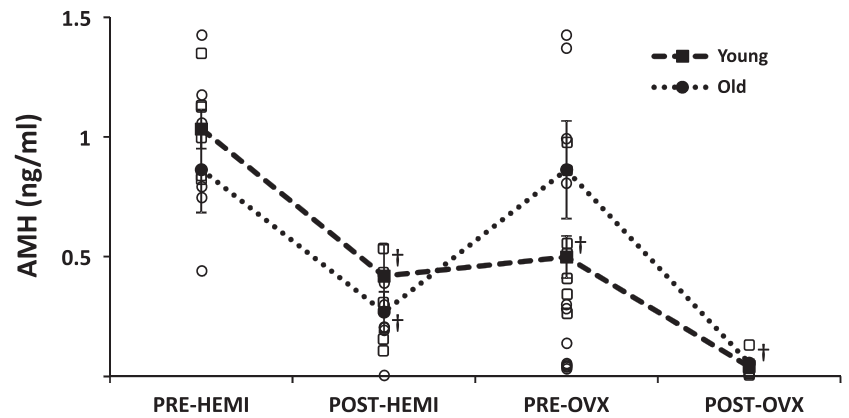

Figure 4

Concentrations of anti-Müllerian hormone $(\mathrm{AMH}, \mathrm{ng} / \mathrm{mL})$ in young $(6.0 \pm 0.8$ years, dashed line, $n=6)$ and old mares $(18.7 \pm 0.5$, dotted line, $n=6$ ) in jugular blood drawn before (PRE-HEMI) and 15 days after (POST-HEMI) hemi-ovariectomy, and before (PRE-OVX) and after (POST-OVX) complete ovariectomy when mares were anestrous. tIndicates concentrations of $\mathrm{AMH}$ were significantly lower $(P<0.01)$ than before hemi-ovariectomy. AMH concentrations were not different between young and old mares before ovariectomy (PRE-OVX) but the age * time interaction was significant $(P<0.02)$. Lines are broken to signify that intervals between post-HEMI and pre-OVX varied ( $111 \pm 24$ days), but data were true longitudinal samples and analyzed as repeated measures accordingly. Means are represented by solid symbols, and individual values from all mares are depicted as open symbols.

on or before the day of surgery and luteolysis occurred at 13 days post surgery. Four others ovulated 1, 4, 4 and 11 days after surgery. Thus, only mares lacking functional CL at surgery ovulated (4/6 mares) during the course of monitoring after surgery, but with variable delays in days to ovulation. Cycle stage at surgery had no apparent effect on the post-surgical decay of AMH concentrations.

The second surgeries to remove the remaining ovary were done when ultrasound imaging and clinical observations indicated mares had become anestrous. Concentrations of AMH before hemi-ovariectomy (preHEMI) and 15 days after hemi-ovariectomy (post-HEMI) were also compared with those at the time of the second surgery (pre-OVX) and after the remaining ovary had been removed (post-OVX; Fig. 4). At the time of the second surgery, AMH concentrations in old mares had recovered to concentrations that were not different from those before hemi-ovariectomy $(0.86 \pm 0.27$ vs $0.86 \pm 0.06 \mathrm{ng} / \mathrm{mL}$, respectively). However, $\mathrm{AMH}$ concentrations at the time of the second surgery in young mares were still half those seen before hemi-ovariectomy $(1.01 \pm 0.42$ vs $0.50 \pm 0.04 \mathrm{ng} / \mathrm{mL}, P<0.01)$. The difference in restoration of AMH concentrations in old vs young mares was supported by a significant interaction of age $\mathrm{x}$ time $(P<0.02)$. However, the mean AMH concentrations in old and young mares at the time of the second surgery (before ovariectomy, pre-OVX) were not significantly different $(P>0.4)$ by multiple comparisons analysis (Fig. 4). Still, old mares 
appeared to recover $\mathrm{AMH}$ production in the months following hemi-ovariectomy, whereas young mares did not. No significant correlations were found between AFC (Supplementary Table 1) and AMH concentrations based on ultrasound examination of ovaries before hemiovariectomy or between AMH prior to the second surgery and AFC determined on the second ovary by MRI.

\section{Discussion}

We report the most comprehensive survey of AMH concentration ever conducted across the lifespan of female horses. It is the most extensive such study completed in any species, except perhaps human (Hagen et al. 2010, Lie Fong et al. 2012, Cui et al. 2016). The analysis of samples from over 1100 females from birth through their third decade of life provides a unique view of how AMH concentrations change with age in this species. The results of a recent longitudinal study in horses indicated that $\mathrm{AMH}$ concentrations were fairly constant during the first 2 years of life and that concentrations at birth were correlated with those at 2 years of age (Scarlet et al. 2018). As the current data illustrate, despite the gradual loss of ovarian follicles that occurs inevitably with age in mammals (Gougeon et al. 1994, Faddy \& Gosden 1995, 1996, Faddy 2000, Bristol-Gould et al. 2006, Hansen et al. 2008, Coxworth \& Hawkes 2010, Monget et al. 2012), it is only after 20 years of age that AMH concentrations begin to decline in mares, and thereafter to decline quite rapidly. Although subject to possible sampling bias due to the many fewer samples collected from mares over 20 years of age than from their younger cohorts, these data are consistent with a previous, smaller but more balanced study of AMH in aging mares (Claes et al. 2015). It is also consistent with observations in pony mares over 20 years of age which exhibited less follicular activity than did younger mares as they transitioned into the breeding season (Carnevale et al. 1997). However, by linear regression analysis there was no decay in AMH concentrations in mares during their first or second decades of life. In fact, when examined by 5 -year intervals, there was an increase in AMH in years 5-15 compared to the interval up to 5 years of age. This pattern of AMH concentration over the lifespan is remarkably similar to that seen in women where it also peaks at about 15 years of age and begins to decline around 20 years of age (Hagen et al. 2010, Lie Fong et al. 2012, Cui et al. 2016). Thus, as is the case in women, AMH appears to be a marker of ovarian senescence in aging mares, but may not accurately reflect ovarian reserve in mares until nearly 20 years of age. Moreover, if the decline in AMH after 20 years of age reflects true ovarian senescence, when it becomes obvious, senescence is not gradual but rather undergoes a rapid acceleration. This has been postulated to occur also in women as they become menopausal (Faddy \& Gosden 1996, Hansen et al. 2008).

Two other observations in the current data set are notable relative to folliculogenesis in horses and other mammals. First, the increase in AMH from 5 to 15 years of age suggests that either a similar number of follicles are secreting more AMH in mid-reproductive life of mares or there are significantly more follicles present secreting $\mathrm{AMH}$. Consistent with the latter possibility, pony mares 15-19 years of age were found to exhibit greater follicular activity in the late luteal phase than did young mares, 5-7 years of age (Carnevale et al. 1993). Studies in horses (Ball et al. 2008) and other species indicate that AMH is expressed and secreted by granulosa cells of pre-antral or early antral follicles (Baarends et al. 1995, Durlinger et al. 1999, Weenen et al. 2004, Sahambi et al. 2008, Rico et al. 2011, Jeppesen et al. 2013) but that AMH expression decreases as antral follicles increase in diameter and become more gonadotropin responsive (Fortune 2003, Fortune et al. 2010). The selective destruction of follicles at these stages of development in mice provides convincing evidence of this (Sahambi et al. 2008). It is not clear what range of follicle populations might be targeted, but vaccination against porcine zona pellucida dramatically decreased AMH in mares (Joone et al. 2018). As noted earlier, immunohistochemical analyses of equine ovaries suggest that AMH expression is higher in secondary and small antral than in large antral follicles (Ball et al. 2008). However, counting follicle numbers requires careful histomorphometric analysis (Forabosco \& Sforza 2007, Hansen et al. 2008) that is methodologically challenging even in the smaller size of the human ovary (Hansen \& Soules 2008) and is well beyond the scope of the present study in the horse. The second notable observation was the high degree of variation in $\mathrm{AMH}$ concentrations in filly foals at birth. This was not observed in a recent study involving a smaller number of filly foals that were included in a longitudinal study (Scarlet et al. 2018). Several of the newborn fillies in the current study had AMH concentrations that were in a range expected of colts (Claes et al. 2013). Given this variability, it is unclear what extremes of variation in follicle populations might exist on the ovaries of at least some foals at birth. If this variability truly exists in larger populations of neonatal fillies, even if significantly correlated with concentrations at 2 years of 
age as previously shown (Scarlet et al. 2018), AMH at birth may not be very predictive of concentrations in later life. Regardless, it is clear that $\mathrm{AMH}$ concentrations actually increase as mares enter their most fertile years, and AMH only begins to reflect diminishing follicular reserves in mares as they approach their third decade of life.

Despite the increase in AMH concentrations from early-to-mid-reproductive life, halving ovarian reserve in both young and old mares almost exactly halved $\mathrm{AMH}$ concentrations. Consistent with the findings of the population-based study, concentrations of AMH were similar in the young and old mares before hemiovariectomy. Similarly, the gradual decline post-surgically, consistent with the extended half-life of AMH in horses (Claes et al. 2013), was essentially identical in both groups of mares. Surgery was conducted without regard for stage of the cycle because AMH concentrations do not change at different stages of the reproductive cycle (Almeida et al. 2011). In the current studies, pre-surgical AFCs by ultrasound of the ovaries were not predictive of AMH concentrations, nor were those of the excised ovary predictive of the subsequent decline in $\mathrm{AMH}$. The random and variable stage of the cycle at the time of examination was likely a significant factor in the variability observed. As noted earlier, this is also consistent with the experimental evidence that follicles, of a size that can be counted non-invasively, likely do not contribute significantly to circulating AMH concentrations (Sahambi et al. 2008, Claes et al. 2016). Follicles of smaller diameter are more numerous (Driancourt et al. 1982a) and therefore contribute most to AFC. Even though losing their ability to secrete $\mathrm{AMH}$, this probably explains the positive correlation between antral follicle count and circulating $\mathrm{AMH}$ in published studies that employed larger numbers of mares and more frequently determined AFC (Claes et al. 2015). The lack of correlation between $\mathrm{AMH}$ and AFC in this study can be attributed to being under-powered with too few mares examined and too few observations on each. To this point, the correlation between AMH concentration and numbers of growing follicles in mice was lost when analysis was conducted on specific days which necessarily limited the number of animals that could be used in that analysis (Sahambi et al. 2008). Regardless, hemi-ovariectomy experimentally validated the accuracy of AMH concentrations as an index of total ovarian reserve in individual young and aging mares.

At least two prior studies have employed hemiovariectomy to investigate folliculogenesis in mares (Driancourt \& Palmer 1984, Sirois et al. 1989). However, only one other study in mammals appears to have utilized hemi-ovariectomy to halve ovarian reserve and examine $\mathrm{AMH}$, a study conducted in cynomolgus macaques (Macaca fascicularis) (Appt et al. 2010). Concurrent treatment with the follicular toxicant VCN in that study confounded results, likely causing a more dramatic reduction in $\mathrm{AMH}$ post-surgically (>60\% (Appt et al. 2010)) than was found here in horses. Uniquely in the current study however, AMH concentrations were also re-assessed several months later before removal of the second remaining ovary. The results were surprising, difficult to explain based on our current understanding, and raise some interesting questions. By the time of the second surgery, the concentrations of AMH in the older mares had returned to levels seen before hemi-ovariectomy. This suggests that the remaining ovary compensated in some way, restoring the total number of AMH-secreting, presumably pre- and early antral follicles previously distributed between both ovaries. Alternatively, if there was no change in their numbers, then expression and secretion of AMH by those follicles must have increased. More puzzling perhaps, a restoration of $\mathrm{AMH}$ concentration was not seen in the younger cohort of mares at the time of the second surgery. However, there was considerable variability in $\mathrm{AMH}$ concentrations, especially in the samples collected before the second surgery. While warranting verification in additional studies including a larger number of mares, the current observations suggest that the longterm effects of hemi-ovariectomy may be an interesting way to investigate the effects of aging on reproductive function. In any case, it seems unlikely that under these experimental circumstances (as with the increase seen between 5 and 15 years of age) AMH concentration reflected ovarian follicular reserve accurately.

There is broad agreement that aging changes not only ovarian function but the reproductive axis in general (Brann \& Mahesh 2005, Prior 2005, Carnevale 2008, Kermath \& Gore 2012, Claes et al. 2017), and this might also have been a significant factor in this study. Consistent with involvement of the hypothalamic-pituitary axis in reproductive aging, the rate of double ovulations increases as mares age (Davies Morel \& O'Sullivan 2001). Perhaps the accelerated decline in AMH concentrations in mares after 20 years of age indicates that changes in neuroendocrine regulation of follicular growth rate or recruitment in aging mares (Carnevale et al. 1993) are somehow amplified or exacerbated by hemi-ovariectomy. Hemi-ovariectomy has been studied in many species including sheep (Duggavathi et al. 2008), cattle (Dean \& Dailey 2011) and pigs (Coleman et al. 1984). Longterm effects on folliculogenesis in sheep indicate that 
ovulatory compensation involves an extension of the normal lifespan of ovulatory-sized follicles (Duggavathi et al. 2008). However, the relationship between hemiovariectomy and aging appears only to have been studied in rats. Initially, ovulatory compensation is apparently due to a decrease in the rate of follicular atresia in the remaining ovary (Hirshfield 1982), but the ability to compensate is eventually lost with age (Peppler 1971). How this might affect AMH secretion is unknown. The phenomenon of compensatory follicular development is complex, affected by age, and is perhaps not the same across species. Histological studies are in progress in the hope of mapping follicles in the ovaries of the young and old mares from this study to better understand the origins of the noted differences in the recovery of AMH concentrations following hemi-castration.

\section{Supplementary data}

This is linked to the online version of the paper at https://doi.org/10.1530/ JOE-18-0391.

\section{Declaration of interest}

The authors declare that there is no conflict of interest that could be perceived as prejudicing the impartiality of the research reported.

\section{Funding}

This work was supported by FAPESP - The São Paulo Research Foundation (Grant numbers 2014/13777-6, 2014/13191-1, 2015/01113-9), by funds from the John $\mathrm{P}$ Hughes Endowment and the Clinical Endocrinology Laboratory, UC Davis School of Veterinary Medicine.

\section{Acknowledgements}

The authors would like to thank Drs Erin Legacki and Phil Kass for their expert help and advice with statistical analysis, Rebecca Cotterman and Casey Hoffmann for laboratory assistance and $\mathrm{Dr}$ Bob Dailey for helpful discussions. In addition, we are extremely grateful to Dr David Pépin, Pediatric Surgical Research Laboratories, Massachusetts General Hospital, Boston, MA, for the very generous gift of purified recombinant human $\mathrm{AMH}$.

\section{References}

Almeida J, Ball BA, Conley AJ, Place NJ, Liu IK, Scholtz EL, Mathewson L, Stanley SD \& Moeller BC 2011 Biological and clinical significance of anti-Müllerian hormone determination in blood serum of the mare. Theriogenology 76 1393-1403. (https://doi.org/10.1016/j. theriogenology.2011.06.008)

Appt SE, Clarkson TB, Chen H, Adams MR, Christian PJ, Hoyer PB, Wilson ME \& Kaplan JR 2009 Serum antimullerian hormone predicts ovarian reserve in a monkey model. Menopause 16 597-601. (https:// doi.org/10.1097/gme.0b013e3181906fb6)

Appt SE, Clarkson TB, Hoyer PB, Kock ND, Goode AK, May MC, Persyn JT, Vail NK, Ethun KF, Chen H, et al. 2010 Experimental induction of reduced ovarian reserve in a nonhuman primate model (Macaca fascicularis). CompMed 60 380-388.

Baarends WM, Uilenbroek JT, Kramer P, Hoogerbrugge JW, van Leeuwen EC, Themmen AP \& Grootegoed JA 1995 Anti-mullerian hormone and anti-mullerian hormone type II receptor messenger ribonucleic acid expression in rat ovaries during postnatal development, the estrous cycle, and gonadotropin-induced follicle growth. Endocrinology 136 4951-4962. (https://doi.org/10.1210/ endo.136.11.7588229)

Ball BA, Conley AJ, MacLaughlin DT, Grundy SA, Sabeur K \& Liu IK 2008 Expression of anti-Mullerian hormone (AMH) in equine granulosacell tumors and in normal equine ovaries. Theriogenology 70 968-977. (https://doi.org/10.1016/j.theriogenology.2008.05.059)

Block E 1952 Quantitative morphological investigations of the follicular system in women; variations at different ages. Acta Anatomica 14 108-123. (https://doi.org/10.1159/000140595)

Brann DW \& Mahesh VB 2005 The aging reproductive neuroendocrine axis. Steroids 70 273-283. (https://doi.org/10.1016/j. steroids.2004.12.008)

Bristol-Gould SK, Kreeger PK, Selkirk CG, Kilen SM, Mayo KE, Shea LD \& Woodruff TK 2006 Fate of the initial follicle pool: empirical and mathematical evidence supporting its sufficiency for adult fertility. Developmental Biology 298 149-154. (https://doi.org/10.1016/j. ydbio.2006.06.023)

Carnevale EM 2008 The mare model for follicular maturation and reproductive aging in the woman. Theriogenology 69 23-30. (https:// doi.org/10.1016/j.theriogenology.2007.09.011)

Carnevale EM, Bergfeld DR \& Ginther OJ 1993 Aging effects on follicular activity and concentrations of $\mathrm{FSH}, \mathrm{LH}$, and progesterone in mares. Animal Reproduction Science 31 287-299. (https://doi. org/10.1016/0378-4320(93)90013-H)

Carnevale EM, Hermenet MJ \& Ginther OJ 1997 Age and pasture effects on vernal transition in mares. Theriogenology 47 1009-1018. (https:// doi.org/10.1016/S0093-691X(97)00058-7)

Casadei L, Manicuti C, Puca F, Madrigale A, Emidi E \& Piccione E 2013 Can anti-Mullerian hormone be predictive of spontaneous onset of pregnancy in women with unexplained infertility? Journal of Obstetrics and Gynaecology 33 857-861. (https://doi.org/10.3109/01443615.201 3.831050)

Claes A, Ball BA, Almeida J, Corbin CJ \& Conley AJ 2013 Serum antiMullerian hormone concentrations in stallions: developmental changes, seasonal variation, and differences between intact stallions, cryptorchid stallions, and geldings. Theriogenology 79 1229-1235. (https://doi.org/10.1016/j.theriogenology.2013.03.019)

Claes A, Ball BA, Scoggin KE, Esteller-Vico A, Kalmar JJ, Conley AJ, Squires EL \& Troedsson MH 2015 The interrelationship between anti-Mullerian hormone, ovarian follicular populations and age in mares. Equine Veterinary Journal 47 537-541. (https://doi.org/10.1111/ evj.12328)

Claes A, Ball BA, Troedsson MH, Curry TE Jr, Squires EL \& Scoggin KE 2016 Molecular changes in the equine follicle in relation to variations in antral follicle count and anti-Mullerian hormone concentrations. Equine Veterinary Journal 48 741-748. (https://doi.org/10.1111/ evj.12514)

Claes A, Ball BA, Scoggin KE, Roser JF, Woodward EM, Davolli GM, Squires EL \& Troedsson MHT 2017 The influence of age, antral follicle count and diestrous ovulations on estrous cycle characteristics of mares. Theriogenology 97 34-40. (https://doi.org/10.1016/j. theriogenology.2017.04.019)

Coleman DA, Fleming MW \& Dailey RA 1984 Factors affecting ovarian compensation after unilateral ovariectomy in gilts. Journal of Animal Science 59 170-176. (https://doi.org/10.2527/jas1984.591170x) 
Conley AJ, Scholtz EL, Dujovne G, Cotterman RF, Legacki EL, Uliani RC, Alvarenga MA, Ball BA, Kalra B, Savjani GV, et al. 2017 Inhibin-A and inhibin-B in cyclic and pregnant mares, and mares with granulosa-theca cell tumors: physiological and diagnostic implications. Theriogenology 108 192-200. (https://doi.org/10.1016/j. theriogenology.2017.12.003)

Coxworth JE \& Hawkes K 2010 Ovarian follicle loss in humans and mice: lessons from statistical model comparison. Human Reproduction $\mathbf{2 5}$ 1796-1805. (https://doi.org/10.1093/humrep/deq136)

Cui L, Qin Y, Gao X, Lu J, Geng L, Ding L, Qu Z, Zhang X \& Chen ZJ 2016 Antimullerian hormone: correlation with age and androgenic and metabolic factors in women from birth to postmenopause. Fertility and Sterility 105 481.e481-485.e481. (https://doi. org/10.1016/j.fertnstert.2015.10.017)

Davies Morel MC \& O'Sullivan JA 2001 Ovulation rate and distribution in the thoroughbred mare, as determined by ultrasonic scanning: the effect of age. Animal Reproduction Science 66 59-70. (https://doi. org/10.1016/S0378-4320(01)00092-6)

Dean M \& Dailey RA 2011 The ability of subordinate follicles of the second follicular wave to become dominant is lost by day 15 of the estrous cycle in cattle. Animal Reproduction Science 126 162-167. (https://doi.org/10.1016/j.anireprosci.2011.06.005)

Driancourt MA \& Palmer E 1984 Time of ovarian follicular recruitment in cyclic pony mares. Theriogenology 21 591-600. (https://doi. org/10.1016/0093-691X(84)90444-8)

Driancourt MA, Mariana JC \& Palmer E 1982a Effect of the stage of the oestrous cycle on the follicular population in pony mares. Reproduction Nutrition Development 22 803-812. (https://doi. org/10.1051/rnd:19820607)

Driancourt MA, Paris A, Roux C, Mariana JC \& Palmer E 1982b Ovarian follicular populations in pony and saddle-type mares. Reproduction Nutrition Development 22 1035-1047. (https://doi.org/10.1051/ rnd:19820714)

Duggavathi R, Bartlewski PM, Barrett DM, Bagu E \& Rawlings NC 2008 Short- and long-term effects of unilateral ovariectomy in sheep: causative mechanisms. Biology of Reproduction $\mathbf{7 8} 490-496$. (https:// doi.org/10.1095/biolreprod.107.064188)

Durlinger AL, Kramer P, Karels B, de Jong FH, Uilenbroek JT, Grootegoed JA \& Themmen AP 1999 Control of primordial follicle recruitment by anti-Mullerian hormone in the mouse ovary. Endocrinology 140 5789-5796. (https://doi.org/10.1210/ endo.140.12.7204)

Faddy MJ 2000 Follicle dynamics during ovarian ageing. Molecular and Cellular Endocrinology 163 43-48. (https://doi.org/10.1016/S03037207(99)00238-5)

Faddy MJ \& Gosden RG 1995 A mathematical model of follicle dynamics in the human ovary. Human Reproduction 10 770-775. (https://doi. org/10.1093/oxfordjournals.humrep.a136036)

Faddy MJ \& Gosden RG 1996 A model conforming the decline in follicle numbers to the age of menopause in women. Human Reproduction 11 1484-1486. (https://doi.org/10.1093/oxfordjournals.humrep. a019422)

Forabosco A \& Sforza C 2007 Establishment of ovarian reserve: a quantitative morphometric study of the developing human ovary. Fertility and Sterility 88 675-683. (https://doi.org/10.1016/j. fertnstert.2006.11.191)

Fortune JE 1994 Ovarian follicular growth and development in mammals. Biology of Reproduction 50 225-232. (https://doi.org/10.1095/ biolreprod50.2.225)

Fortune JE 2003 The early stages of follicular development: activation of primordial follicles and growth of preantral follicles. Animal Reproduction Science 78 135-163. (https://doi.org/10.1016/S03784320(03)00088-5)

Fortune JE, Yang MY \& Muruvi W 2010 The earliest stages of follicular development: follicle formation and activation. Society of Reproduction and Fertility Supplement 67 203-216.
Gosden RG \& Faddy MJ 1998 Biological bases of premature ovarian failure. Reproduction, Fertility and Development 10 73-78. (https://doi. org/10.1071/R98043)

Gougeon A 1996 Regulation of ovarian follicular development in primates: facts and hypotheses. Endocrine Reviews 17 121-155. (https://doi.org/10.1210/edrv-17-2-121)

Gougeon A, Ecochard R \& Thalabard JC 1994 Age-related changes of the population of human ovarian follicles: increase in the disappearance rate of non-growing and early-growing follicles in aging women. Biology of Reproduction 50 653-663. (https://doi.org/10.1095/ biolreprod50.3.653)

Hagen CP, Aksglaede L, Sorensen K, Main KM, Boas M, Cleemann L, Holm K, Gravholt CH, Andersson AM, Pedersen AT, et al. 2010 Serum levels of anti-Mullerian hormone as a marker of ovarian function in 926 healthy females from birth to adulthood and in 172 Turner syndrome patients. Journal of Clinical Endocrinology and Metabolism 95 5003-5010. (https://doi.org/10.1210/jc.2010-0930)

Hansen KR \& Soules MR 2008 Counting ovarian follicles is not without its challenges. Fertility and Sterility 89 1028-1029; author reply 1029. (https://doi.org/10.1016/j.fertnstert.2008.01.023)

Hansen KR, Knowlton NS, Thyer AC, Charleston JS, Soules MR \& Klein NA A new model of reproductive aging: the decline in ovarian non-growing follicle number from birth to menopause. Human Reproduction 23 699-708. (https://doi.org/10.1093/humrep/dem408)

Hirshfield AN 1982 Follicular recruitment in long-term hemicastrate rats. Biology of Reproduction 27 48-53. (https://doi.org/10.1095/ biolreprod27.1.48)

Hoyer PB \& Sipes IG 1996 Assessment of follicle destruction in chemicalinduced ovarian toxicity. Annual Review of Pharmacology and Toxicology 36 307-331. (https://doi.org/10.1146/annurev.pa.36.040196.001515)

Ireland JJ, Smith GW, Scheetz D, Jimenez-Krassel F, Folger JK, Ireland JL, Mossa F, Lonergan P \& Evans AC 2011 Does size matter in females? An overview of the impact of the high variation in the ovarian reserve on ovarian function and fertility, utility of anti-Mullerian hormone as a diagnostic marker for fertility and causes of variation in the ovarian reserve in cattle. Reproduction, Fertility and Development 23 1-14. (https://doi.org/10.1071/RD10226)

Jeppesen JV, Anderson RA, Kelsey TW, Christiansen SL, Kristensen SG, Jayaprakasan K, Raine-Fenning N, Campbell BK \& Yding Andersen C 2013 Which follicles make the most anti-Mullerian hormone in humans? Evidence for an abrupt decline in $\mathrm{AMH}$ production at the time of follicle selection. Molecular Human Reproduction 19 519-527. (https://doi.org/10.1093/molehr/gat024)

Jimenez-Krassel F, Scheetz DM, Neuder LM, Ireland JL, Pursley JR, Smith GW, Tempelman RJ, Ferris T, Roudebush WE, Mossa F, et al. 2015 Concentration of anti-Mullerian hormone in dairy heifers is positively associated with productive herd life. Journal of Dairy Science 98 3036-3045. (https://doi.org/10.3168/jds.2014-8130)

Joone CJ, Schulman ML, Fosgate GT, Claes ANJ, Gupta SK, Botha AE, Human A \& Bertschinger HJ 2018 Serum anti-Mullerian hormone dynamics in mares following immunocontraception with anti-zona pellucida or -GnRH vaccines. Theriogenology 106 214-220. (https:// doi.org/10.1016/j.theriogenology.2017.10.004)

Kano M, Sosulski AE, Zhang L, Saatcioglu HD, Wang D, Nagykery N, Sabatini ME, Gao G, Donahoe PK \& Pepin D 2017 AMH/MIS as a contraceptive that protects the ovarian reserve during chemotherapy. PNAS 114 E1688-E1697. (https://doi.org/10.1073/pnas.1620729114)

Kermath BA \& Gore AC 2012 Neuroendocrine control of the transition to reproductive senescence: lessons learned from the female rodent model. Neuroendocrinology 96 1-12. (https://doi. org/10.1159/000335994)

Kevenaar ME, Meerasahib MF, Kramer P, van de Lang-Born BM, de Jong FH, Groome NP, Themmen AP \& Visser JA 2006 Serum antimullerian hormone levels reflect the size of the primordial follicle pool in mice. Endocrinology 147 3228-3234. (https://doi.org/10.1210/ en.2005-1588) 
Knight PG \& Glister C 2006 TGF-beta superfamily members and ovarian follicle development. Reproduction 132 191-206. (https://doi. org/10.1530/rep.1.01074)

Leonhardt H, Gull B, Stener-Victorin E \& Hellstrom M 2014 Ovarian volume and antral follicle count assessed by MRI and transvaginal ultrasonography: a methodological study. Acta Radiologica 55 248-256. (https://doi.org/10.1177/0284185113495835)

Lie Fong S, Visser JA, Welt CK, de Rijke YB, Eijkemans MJ, Broekmans FJ, Roes EM, Peters WH, Hokken-Koelega AC, Fauser BC, et al. 2012 Serum anti-mullerian hormone levels in healthy females: a nomogram ranging from infancy to adulthood. Journal of Clinical Endocrinology and Metabolism 97 4650-4655. (https://doi.org/10.1210/ jc.2012-1440)

Mark-Kappeler CJ, Sen N, Keating AF, Sipes IG \& Hoyer PB 2010 Distribution and responsiveness of rat anti-Mullerian hormone during ovarian development and VCD-induced ovotoxicity. Toxicology and Applied Pharmacology 249 1-7. (https://doi.org/10.1016/j. taap.2010.08.024)

Monget P, Bobe J, Gougeon A, Fabre S, Monniaux D \& Dalbies-Tran R 2012 The ovarian reserve in mammals: a functional and evolutionary perspective. Molecular and Cellular Endocrinology 356 2-12. (https:// doi.org/10.1016/j.mce.2011.07.046)

Monniaux D, Clement F, Dalbies-Tran R, Estienne A, Fabre S, Mansanet C \& Monget P 2014 The ovarian reserve of primordial follicles and the dynamic reserve of antral growing follicles: what is the link? Biology of Reproduction 90 85. (https://doi.org/10.1095/ biolreprod.113.117077)

Mossa F, Jimenez-Krassel F, Scheetz D, Weber-Nielsen M, Evans ACO \& Ireland JJ 2017 Anti-Mullerian Hormone (AMH) and fertility management in agricultural species. Reproduction 154 R1-R11. (https://doi.org/10.1530/REP-17-0104)

Munro C \& Stabenfeldt G 1984 Development of a microtitre plate enzyme immunoassay for the determination of progesterone. Journal of Endocrinology 101 41-49. (https://doi.org/10.1677/joe.0.1010041)

Pepin D, Hoang M, Nicolaou F, Hendren K, Benedict LA, Al-Moujahed A, Sosulski A, Marmalidou A, Vavvas D \& Donahoe PK 2013 An albumin leader sequence coupled with a cleavage site modification enhances the yield of recombinant C-terminal Mullerian Inhibiting Substance. Technology 1 63-71. (https://doi.org/10.1142/S2339547813500076)

Peppler RD 1971 Effects of unilateral ovariectomy on follicular development and ovulation in cycling, aged rats. American Journal of Anatomy 132 423-427. (https://doi.org/10.1002/aja.1001320403)

Prior JC 2005 Ovarian aging and the perimenopausal transition: the paradox of endogenous ovarian hyperstimulation. Endocrine 26 297-300. (https://doi.org/10.1385/ENDO:26:3:297)

Rico C, Medigue C, Fabre S, Jarrier P, Bontoux M, Clement F \& Monniaux D 2011 Regulation of anti-Mullerian hormone production in the cow: a multiscale study at endocrine, ovarian, follicular, and granulosa cell levels. Biology of Reproduction 84 560-571. (https://doi. org/10.1095/biolreprod.110.088187)
Roosa KA, Zysling DA \& Place NJ 2015 An assessment of anti-Mullerian hormone in predicting mating outcomes in female hamsters that have undergone natural and chemically-accelerated reproductive aging. General and Comparative Endocrinology 214 56-61. (https://doi. org/10.1016/j.ygcen.2015.03.007)

Sahambi SK, Visser JA, Themmen AP, Mayer LP \& Devine PJ 2008 Correlation of serum anti-Mullerian hormone with accelerated follicle loss following 4-vinylcyclohexene diepoxide-induced follicle loss in mice. Reproductive Toxicology 26 116-122. (https://doi.org/10.1016/j. reprotox.2008.07.005)

Scarlet D, Wulf M, Kuhl J, Kohne M, Ille N, Conley AJ \& Aurich C 2018 Anti-Mullerian hormone profiling in prepubertal horses and its relationship with gonadal function. Theriogenology 117 72-77. (https://doi.org/10.1016/j.theriogenology.2018.05.012)

Sirois J, Ball BA \& Fortune JE 1989 Patterns of growth and regression of ovarian follicles during the oestrous cycle and after hemiovariectomy in mares. Equine Veterinary Journal 21 43-48. (https://doi. org/10.1111/j.2042-3306.1989.tb04672.x)

Smith BJ, Mattison DR \& Sipes IG 1990 The role of epoxidation in 4-vinylcyclohexene-induced ovarian toxicity. Toxicology and Applied Pharmacology 105 372-381. (https://doi.org/10.1016/0041008X(90)90141-G)

Streuli I, de Mouzon J, Paccolat C, Chapron C, Petignat P, Irion OP \& de Ziegler D 2014 AMH concentration is not related to effective time to pregnancy in women who conceive naturally. Reproductive BioMedicine Online 28 216-224. (https://doi.org/10.1016/j.rbmo.2013.10.007)

van Disseldorp J, Faddy MJ, Themmen AP, de Jong FH, Peeters PH, van der Schouw YT \& Broekmans FJ 2008 Relationship of serum antimullerian hormone concentration to age at menopause. Journal of Clinical Endocrinology and Metabolism 93 2129-2134. (https://doi. org/10.1210/jc.2007-2093)

Van Kempen TA, Milner TA \& Waters EM 2011 Accelerated ovarian failure: a novel, chemically induced animal model of menopause. Brain Research 1379 176-187. (https://doi.org/10.1016/j. brainres.2010.12.064)

Wallace WH \& Kelsey TW 2010 Human ovarian reserve from conception to the menopause. PLOS ONE 5 e8772. (https://doi.org/10.1371/ journal.pone.0008772)

Walt ML, Stabenfeldt GH, Hughes JP, Neely DP \& Bradbury R 1979 Development of the equine ovary and ovulation fossa. Journal of Reproduction and Fertility Supplements 27 471-477.

Weenen C, Laven JS, Von Bergh AR, Cranfield M, Groome NP, Visser JA, Kramer P, Fauser BC \& Themmen AP 2004 Anti-Mullerian hormone expression pattern in the human ovary: potential implications for initial and cyclic follicle recruitment. Molecular Human Reproduction 10 77-83. (https://doi.org/10.1093/molehr/gah015)

Yeh J, Kim B, Peresie J, Liang YJ \& Arroyo A 2007 Serum and ovarian Mullerian inhibiting substance, and their decline in reproductive aging. Fertility and Sterility 87 1227-1230. (https://doi.org/10.1016/j. fertnstert.2006.11.011)

Received in final form 17 October 2018

Accepted 26 October 2018

Accepted Preprint published online 1 November 2018 https://joe.bioscientifica.com https://doi.org/10.1530/JOE-18-0391 (c) 2019 Society for Endocrinology Published by Bioscientifica Ltd. Printed in Great Britain 